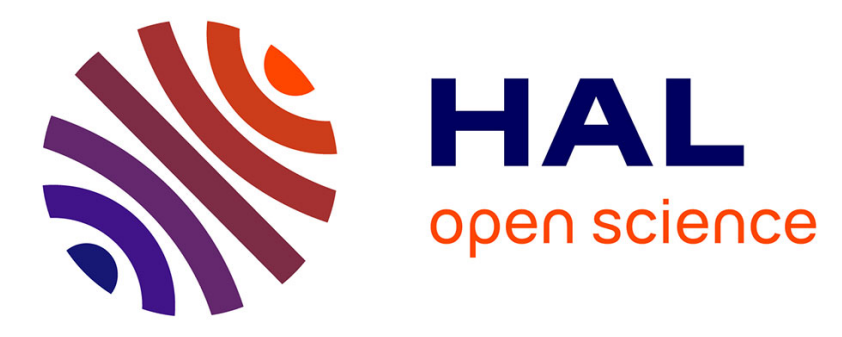

\title{
Novel targeted approach to better understand how natural structural barriers govern carotenoid in vitro bioaccessibility in vegetable-based systems
}

Paola Palmero, Lien Lemmens, Albert Ribas-Agusti, Carola Sosa, Kristof Met, Jean de Dieu Umutoni, Marc Hendrickx, Ann van Loey

\section{To cite this version:}

Paola Palmero, Lien Lemmens, Albert Ribas-Agusti, Carola Sosa, Kristof Met, et al.. Novel targeted approach to better understand how natural structural barriers govern carotenoid in vitro bioaccessibility in vegetable-based systems. Food Chemistry, 2013, 141 (3), pp.2036-2043. 10.1016/j.foodchem.2013.05.064 . hal-02647793

\section{HAL Id: hal-02647793 \\ https: / hal.inrae.fr/hal-02647793}

Submitted on 29 May 2020

HAL is a multi-disciplinary open access archive for the deposit and dissemination of scientific research documents, whether they are published or not. The documents may come from teaching and research institutions in France or abroad, or from public or private research centers.
L'archive ouverte pluridisciplinaire HAL, est destinée au dépôt et à la diffusion de documents scientifiques de niveau recherche, publiés ou non, émanant des établissements d'enseignement et de recherche français ou étrangers, des laboratoires publics ou privés. 


\title{
Novel targeted approach to better understand how natural structural barriers govern carotenoid in vitro bioaccessibility in vegetable-based systems
}

\author{
Paola Palmero ${ }^{1}$, Lien Lemmens ${ }^{1}$, Albert Ribas-Agustí, Carola Sosa, Kristof Met, Jean de Dieu Umutoni, \\ Marc Hendrickx, Ann Van Loey*
}

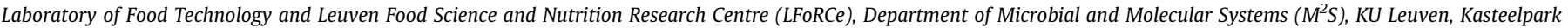
Arenberg 22, 3001 Leuven, Belgium

Keywords:

Bioaccessibility

Carotenoids

Carrot

Natural structural barriers

Tomato

\begin{abstract}
A B S T R A C T
An experimental approach, allowing us to understand the effect of natural structural barriers (cell walls, chromoplast substructures) on carotenoid bioaccessibility, was developed. Different fractions with different levels of carotenoid bio-encapsulation (carotenoid-enriched oil, chromoplasts, small cell clusters, and large cell clusters) were isolated from different types of carrots and tomatoes. An in vitro method was used to determine carotenoid bioaccessibility.

In the present work, a significant decrease in carotenoid in vitro bioaccessibility could be observed with an increasing level of bio-encapsulation. Differences in cell wall material and chromoplast substructure between matrices influenced carotenoid release and inclusion in micelles. For carrots, cell walls and chromoplast substructure were important barriers for carotenoid bioaccessibility while, in tomatoes, the chromoplast substructure represented the most important barrier governing bioaccessibility. The highest increase in carotenoid bioaccessibility, for all matrices, was obtained after transferring carotenoids into the oil phase, a system lacking cell walls and chromoplast substructures that could hamper carotenoid release.
\end{abstract}

\section{Introduction}

Epidemiological studies often relate a healthy lifestyle, in which the consumption of adequate amounts of fruit and vegetables is important, to a reduced risk of chronic diseases such as cardiovascular diseases and cancers (Key, 2011; Ness \& Powles, 1997; Steinmetz \& Potter, 1996; Van't Veer et al., 2000). The health-related benefits that are associated with the consumption of fruit and vegetables, can be attributed to the presence of various bioactive compounds, of which micronutrients form an important class (Key, 2011; Van't Veer et al., 2000). Carotenoids, a group of natural food pigments, are major contributors to the nutritional value of several fruits and vegetables (Rao \& Rao, 2007).

Carotenoids are isoprenoid compounds which typically have a tetraterpenoid structure, implying a long chain of conjugated double bonds. Due to their chemical structure, carotenoids are highly lipophilic molecules (Britton, 1995). In fruit and vegetable tissues,

* Corresponding author. Address: Laboratory of Food Technology, Department of Microbial and Molecular Systems $\left(\mathrm{M}^{2} \mathrm{~S}\right)$, KU Leuven, Kasteelpark Arenberg 23, Postbox 2457, B-3001 Leuven, Belgium. Tel.: +32 163215 67; fax: +32 16321960 .

E-mail address: ann.vanloey@biw.kuleuven.be (A. Van Loey).

1 These authors contributed equally to this work. specific structures are developed in chloroplasts and chromoplasts to sequester and store large amounts of carotenoids (Vishnevetsky, Ovadis, \& Vainstein, 1999). Their lipophilic nature and their specific localisation in plant tissues (i.e. attached to cellular components and surrounded by organelle membranes, cell membrane and cell wall), hamper the absorption of carotenoids from fruits and vegetables in the human tract (Rich et al., 2003). This has been and still is an issue for food technologists and food processors. In this context, the concepts of carotenoid bioaccessibility and bioavailability are to be defined. Carotenoid bioaccessibility refers to the fraction of ingested carotenoids that is released from the food matrix and incorporated into micelles during digestion in the gastrointestinal tract, and thus becomes available for intestinal absorption. The amount of carotenoids that is bioavailable is always less than the amount that is bioaccessible, since carotenoid bioavailability additionally takes into account the fraction that is available for utilisation in normal physiological functions or for storage in the human body (Holst \& Williamson, 2008; Parada \& Aguilera, 2007).

In the literature, several studies describe the carotenoid bioaccessibility in fruit- and vegetable-based food products (e.g. Granado-Lorencio et al., 2007; O'Connell et al., 2007; O'Sullivan et al., 2010; Reboul et al., 2006; Ryan, O'Connell, O'Sullivan, 
Aherne, \& O’Brien, 2008; Veda, Kamath, Platel, Begum, \& Srinivasan, 2006; etc.). However, only a few authors have linked the observations for carotenoid bioaccessibility to structural characteristics of the food products (e.g. Lemmens, Van Buggenhout, Oey, Van Loey, \& Hendrickx, 2009 (carotenoid bioaccessibility - pectin properties); Bengtsson, Brackmann, Enejder, Alminger, \& Svanberg, 2010 (carotenoid bioaccessibility - microstructure); Colle, Van Buggenhout, Van Loey, \& Hendrickx, 2010 (carotenoid bioaccessibility - strength of fibre network); Lemmens, Van Buggenhout, Van Loey, \& Hendrickx, 2010 (carotenoid bioaccessibility - particle size); Tydeman et al., 2010 (carotenoid bioaccessibility - microstructure); Knockaert, Lemmens, Van Buggenhout, Hendrickx, \& Van Loey, 2012 (carotenoid bioaccessibility - microstructure)). Reviews by Waldron, Parker, and Smith (2003), Parada and Aguilera (2007) and Van Buggenhout et al. (2010) have stressed the importance of the association between food structure and nutrient bioaccessibility. However, studies identifying and directly investigating the role of structural barriers against carotenoid bioaccessibility in fruit- and vegetable-based food products are lacking. In our opinion, such studies might give useful explanations and better insights of how crucial structural parameters can determine carotenoid bioaccessibility in fruit- and vegetable-based food products. Recently, some initiatives in this direction have been taken. Schweiggert, Mezger, Schimpf, Steingass, and Carle (2012) studied the relationship between chromoplast morphology and carotenoid bioaccessibility in different matrices, and found a strong correlation between the physical state of the chromoplast substructures and the efficiency of carotenoid release during digestion. Jeffery, Holzenburg, and King (2012) and Jeffery, Turner, and King (2012) studied different fruit and vegetable purees microscopically (cell wall thickness, cell size) (Jeffery, Holzenburg, et al., 2012) and they tried to link these observations with the carotenoid bioaccessibility results obtained for the same purees (Jeffery, Turner, et al., 2012). They concluded that the cell wall and the chromoplast substructures form the most important barriers against carotenoid release during digestion. Moreover, it turned out that a high amount of large plant cells, a low density of cell wall material and a high concentration of plastoglobuli (containing the carotenoids) are factors favouring carotenoid bioaccessibility (Jeffery, Turner, et al., 2012). However, for these experiments, it should be kept in mind that, during the mixing/blending process to obtain fruit and vegetable purees, a complex environment is created, which could lead to difficulties in the interpretation of the results. For example, it is possible that additional structural networks are being formed during mixing which entail new processed-induced barriers against carotenoid release during digestion, next to and/or replacing the natural barriers present in the fruit and vegetable matrix. Such examples have already been cited by Colle, Van Buggenhout, Lemmens, Van Loey, and Hendrickx (2012) and Anese, Mirolo, Beraldo, and Lippe (2013), respectively, in the framework of the effect of high pressure homogenisation and ultrasound treatments on tomato pulp microstructure and lycopene in vitro bioaccessibility.

Therefore, in this study, a specific experiment (including different matrices, different types of carotenoids, and different levels of bio-encapsulation) was designed to evaluate the role of natural barriers in carotenoid bioaccessibility. The fruit and vegetable matrices included in this study (orange carrots, red carrots, orange tomatoes, red tomatoes) were not used as such (e.g. as a puree), but specific fractions were isolated, each representing a different number of barriers encapsulating the carotenoids. The fractions included a carotenoid-enriched oil, a chromoplast, a small/single cell cluster and a large cell/multicellular cluster. In this way, a systematic and detailed understanding of the role of different structural barriers for the carotenoid bioaccessibility could be obtained. Carotenoids with different polarities ( $\beta$-carotene, $\zeta$-carotene and lycopene) in different matrices (e.g. carrot, tomato) were included.

\section{Materials and methods}

\subsection{Materials}

Red tomatoes (Lycopersicon esculentum cv. Patrona) were obtained from a Spanish supplier. Orange tomatoes (Lycopersicon esculentum cv. Bolzano) were purchased in an auction in Mechelen, Belgium. The two types of tomatoes were cut, frozen with liquid nitrogen, and stored at $-40{ }^{\circ} \mathrm{C}$, until the start of the experiments.

Orange carrots (Daucus carota cv. Nerac) and red carrots (unknown Indian variety) were obtained fresh from local shops in Belgium and stored briefly at $4{ }^{\circ} \mathrm{C}$, prior to their use for the experiments.

\subsection{Experimental set-up}

In order to study the different physical barriers that determine the carotenoid in vitro bioaccessibility, various fractions from red tomatoes, red carrots, orange carrots and orange tomatoes were isolated. The fractions prepared include a carotenoid-enriched oil fraction, a chromoplast fraction, a small cell cluster fraction, and a large cell cluster fraction. The concomitant physical barriers surrounding the carotenoids were assumed to be the chromoplast structure/organisation, and (multiple) cell membranes and cell walls. An in vitro bioaccessibility assay was performed on each fraction. Light microscopy was used to visualise the chromoplast and small cell cluster fractions and to observe the structural characteristics of barriers involved. Fig. 1 represents a schematic overview of the experimental set-up.

\subsection{Preparation of carotenoid-containing fractions with different barrier properties}

\subsubsection{Carotenoid-enriched oil fraction}

Lycopene from red carrots and red tomatoes, $\beta$-carotene from orange carrots and $\zeta$-carotene from orange tomatoes were extracted in olive oil.

To produce carotenoid-enriched oil fractions, carrots were peeled, cut into small pieces, mixed with deionized water $(1: 1)$ and blended (Waring Commercial, Torrington, CT, USA) for 1 min. Tomatoes were thawed, peeled, mixed three times (Büchi B-400 mixer, Flawil, Switzerland) for $5 \mathrm{~s}$ and then sieved to remove the seeds.

According to the method described by Colle et al. (2010), the obtained carrot and tomato purees were homogenised (Panda 2 K, Gea Niro Soavi, Parma, Italy) at 1000 bar for one cycle to decrease the particle size and facilitate the release of carotenoids from the matrix. Purees were then mixed with olive oil (ratio puree-oil 5:1) for $5 \mathrm{~h}$ while rotating, end-over-end. The carotenoid-enriched oil fraction was separated by centrifugation (J2 - HS centrifuge, Beckman, J2 - HS centrifuge, Palo Alto, CA, USA) at $18,900 \mathrm{~g}, 4^{\circ} \mathrm{C}$ for $15 \mathrm{~min}$. The carotenoid-enriched oil fraction was isolated and emulsified ( $5 \%$ carotenoid-enriched oil in water emulsion) with a $1 \%$ of $\mathrm{L}-\alpha$-phosphatidylcholine solution. The emulsion was stabilized by homogenisation (Gea Niro Soavi, Parma, Italy) at 1000 bar for one cycle.

\subsubsection{Chromoplast fraction}

The chromoplast fraction was obtained by following the procedure of Hansen and Chiu (2005) with some modifications. Both types of carrots and tomatoes (previously defrosted) were cut into pieces and mixed in a blender (Waring Commercial, Torrington, CT, USA) for $5 \mathrm{~s}$ with $0.05 \mathrm{M}$ EDTA solution (1:1 ratio).

The obtained purees were filtrated using a cheesecloth. The filtrate was centrifuged (Beckman, J2-HS Centrifuge, Palo Alto, CA, 


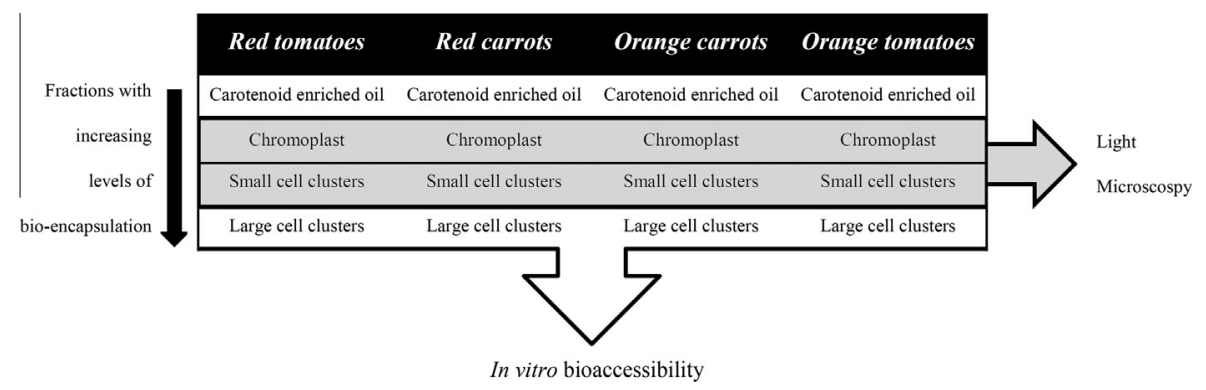

Fig. 1. Overview of the experimental set-up.

USA) at $27,200 \mathrm{~g}, 4^{\circ} \mathrm{C}$ for $30 \mathrm{~min}$. The pellet, which corresponds to the chromoplast-enriched fraction, was re-dissolved in $100 \mathrm{ml}$ of deionized water.

\subsubsection{Cell cluster fractions}

Cell cluster fractions were obtained by separating the particles of tomato and carrot purees into different sizes with a wet sieving equipment (Retsch AS200, Haan, Germany). The carrot and tomato purees were prepared as described in the section on the carotenoid-enriched oil fraction.

In the case of carrot purees, the size of the fraction considered as "small cell clusters" was $40-250 \mu \mathrm{m}$, whereas cell clusters within a size of $800-2000 \mu \mathrm{m}$ were isolated and corresponded to the "large cell clusters". These ranges were determined according to the data reported by Lemmens et al. (2010) and confirmed by light microscopy observations, obtaining mean diameters of $62.9 \pm 22.5$ and $61.4 \pm 15.2 \mu \mathrm{m}$ for red carrot cells and orange carrot cells, respectively.

For the tomato purees, the collected fractions, ranging from 160 to $500 \mu \mathrm{m}$ and from 1000 to $1400 \mu \mathrm{m}$ corresponded to "small cell clusters" and "large cell clusters", respectively. These ranges were based on the data reported by Cheniclet et al. (2005), and on diameters of $446.4 \pm 216.5$ and $495.2 \pm 272.5 \mu \mathrm{m}$, obtained by light microscopy, respectively, for red and orange tomato cells.

\subsection{Light microscopy}

Unstained carrot and tomato fractions were examined under an Olympus BX-41 light microscope (Olympus, Tokyo, Japan) equipped with an Olympus XC50 CCD camera (Olympus, Tokyo, Japan). Cell dimensions were measured from pictures obtained at $\times 10$ and $\times 40$ magnifications, using Cell ${ }^{*}$ software (Olympus, Tokyo, Japan). The chromoplast fraction of the different matrices was analysed with $\times 100$ oil objective lens.

\subsection{Carotenoid concentration}

Carotenoids (lycopene, $\beta$-carotene and $\zeta$-carotene) were extracted from each fraction according to the method described by Sadler, Davis, and Dezman (1990) and Lemmens et al. (2010) with some modifications. Sodium chloride was added to a specific weight of the samples and then mixed for 20 min at $4{ }^{\circ} \mathrm{C}$ by continuous stirring with $50 \mathrm{ml}$ of extraction solution, which consisted of hexane:acetone:ethanol $(50: 25: 25 \mathrm{v} / \mathrm{v} / \mathrm{v})$ with $0.1 \%$ of butylated hydroxytoluene. The stirring was continued for $10 \mathrm{~min}$ at $4{ }^{\circ} \mathrm{C}$ after adding $15 \mathrm{ml}$ of reagent grade water $(18.2 \mathrm{M} \Omega \mathrm{cm})$.

The organic phase, containing the carotenoids, was separated from the polar phase in a separation funnel. The separation was performed under subdued light conditions, in order to prevent carotenoid isomerization and degradation. The organic phase was filtered (Chromafil PET filters, $0.2 \mu \mathrm{m}$ pore size- $25 \mathrm{~mm}$ diameter), and transferred into a dark vial for HPLC analysis.
The identification and quantification of carotenoids were achieved using an HPLC system equipped with a diode array detector (Agilent Technologies 1200 Series, Dinslaken, Belgium). A $\mathrm{C}_{30^{-}}$ column $(3 \mu \mathrm{m} \times 150 \mathrm{~mm} \times 4.6 \mathrm{~mm}$, YMC Europe, Dinslaken, Germany) was used to separate the carotenoids.

A linear gradient was applied to separate carotenoids. The starting conditions were $81 \%$ methanol, $15 \%$ methyl-t-butyl-ether and $4 \%$ reagent grade water. The end conditions for all-trans-lycopene determination were $16 \%$ methanol, $80 \%$ methyl-t-butyl-ether and $4 \%$ reagent grade water $(18.2 \mathrm{M} \Omega \mathrm{cm})$ and, in the case of alltrans- $\beta$-carotene and all-trans- $\zeta$-carotene, the end conditions corresponded to $41 \%$ methanol, $55 \%$ methyl-t-butyl-ether and $4 \%$ reagent grade water $(18.2 \mathrm{M} \Omega \mathrm{cm})$. The gradient was built up in $38 \mathrm{~min}$ for all-trans-lycopene analysis and in $17 \mathrm{~min}$ for all-trans$\beta$-carotene and all-trans- $\zeta$-carotene analyses, with a constant flow rate of $1 \mathrm{ml} / \mathrm{min}$. The column temperature was kept at $25^{\circ} \mathrm{C}$ and the auto-sampler at $4{ }^{\circ} \mathrm{C}$ during the analyses. Identification and quantification were performed at $472 \mathrm{~nm}$ for all-trans-lycopene and $450 \mathrm{~nm}$ for all-trans- $\beta$-carotene and all-trans- $\zeta$-carotene.

Standards for all-trans-lycopene, all-trans- $\beta$-carotene, and alltrans- $\zeta$-carotene (CaroteNature, Lupsingen, Switzerland) were used to identify and quantify each carotenoid, using calibration curves.

The $\zeta$-carotene in orange tomatoes, was identified by retention time and DAD spectra with the standard. However, DAD spectra clearly showed that the compound identified was not purely $\zeta$-carotene. Other structurally similar carotenoid might be present as well, such as pro-lycopene, identified before in orange tomatoes by Mackinney and Jenkins (1949), having a maximal absorption at $400-430 \mathrm{~nm}$. Nevertheless, in this study, our results on orange tomatoes, are expressed as equivalents of $\zeta$-carotene as one of the major compounds.

\subsection{Carotenoid in vitro bioaccessibility}

The in vitro digestion procedure was based on the method described by Lemmens et al. (2010), where stomach and small intestinal digestion were simulated.

Gastric digestion consisted of the addition of $5 \mathrm{ml}$ of $\mathrm{NaCl} /$ ascorbic acid solution $(0.9 \% \mathrm{NaCl}, 1 \%$ ascorbic acid in water) and $5 \mathrm{ml}$ of electrolyte solution $\left(0.3 \% \mathrm{NaCl}, 0.11 \% \mathrm{KCl}, 0.15 \% \mathrm{CaCl}_{2} \cdot 2 \mathrm{H}_{2}\right.$ $\mathrm{O}, 0.05 \% \mathrm{KH}_{2} \mathrm{PO}_{4}$ and $0.07 \% \mathrm{MgCl}_{2} \cdot 6 \mathrm{H}_{2} \mathrm{O}$ ) to a specific amount of each fraction. The $\mathrm{pH}$ was adjusted to $4 \pm 0.05$ and $5 \mathrm{ml}$ of gastric pepsin solution ( $0.52 \%$ porcine pepsin in electrolyte solution) were added. The headspace of the tubes was flushed with $\mathrm{N}_{2}$ and the samples were incubated at $37{ }^{\circ} \mathrm{C}$ while shaking, end-over-end, for $30 \mathrm{~min}$. The $\mathrm{pH}$ was then adjusted to $2 \pm 0.05$ and the headspace was again flushed with $\mathrm{N}_{2}$ and incubated for 30 min under the same conditions.

The small intestinal digestion was simulated by adjusting the $\mathrm{pH}$ to $6.9 \pm 0.05$ and adding $6 \mathrm{ml}$ of pancreatin/bile solution $(0.2 \%$ lipase from porcine pancreas, $0.4 \%$ porcine pancreatin, $2.5 \%$ bile extract, $0.5 \%$ pyrogallol and $1 \%$ tocopherol in water). The headspaces 
of the tubes were flushed with $\mathrm{N}_{2}$ and the samples were incubated for $2 \mathrm{~h}$ at $37^{\circ} \mathrm{C}$ while shaking, end-over-end.

After digestion, samples were ultracentrifuged (Beckman, L7 Ultracentrifuge, Palo Alto, CA, USA) at $165,000 \mathrm{~g}, 4^{\circ} \mathrm{C}$ for $65 \mathrm{~min}$. The soluble part, corresponding to the carotenoids incorporated into the micelles, was isolated. Carotenoids were extracted and quantified according to the procedure described above.

In the case of tomato samples, after phase separation in the funnel, the organic phase was concentrated, using a rotatory evaporator at $30^{\circ} \mathrm{C}$ for $35 \mathrm{~min}$. The concentrated extract was then redissolved in $400 \mu \mathrm{l}$ of hexane:dichloromethane (4:1). A known amount of $\beta$-apo- $8^{\prime}$-carotenal was used to calculate the concentration factor.

To determine the carotenoid bioaccessibility of the chromoplast and the small and large cell cluster fractions, $10 \mathrm{ml}$ of an emulsion ( $5 \%$ olive oil in water, $1 \% \mathrm{~L}-\alpha$-phosphatidylcholine), were added at the beginning of the in vitro digestion assay. The emulsion was incorporated into the fractions that did not contain oil in order to obtain a carotenoid/oil ratio similar to that of the carotenoid-enriched oil fraction.

It should be kept in mind that phospholipids stabilizing the emulsions could decrease the transfer of carotenoids to the oil phase (Degrou, George, Renard, \& Page, 2013). For the cell clusters and chromoplast fractions, the oil emulsion stabilized with $L-\alpha-$ phosphatidylcholine, added before the in vitro bioaccessibility procedure, could form an important barrier against carotenoids diffusing into oil. The same case will apply for the enriched oil phase fractions that were stabilized with the same emulsifier. Nevertheless, our results are comparable between each other, as the amount of phospholipids present was the same for the different fractions on the four matrices.

Measurements of the carotenoid concentration and carotenoid in vitro bioaccessibility of each fraction were performed in triplicate. Results are shown as the ratio of the bioaccessible carotenoids to the initial carotenoid concentration in the sample $(\mathrm{B} / \mathrm{C})$.

\subsection{Data analysis}

In order to identify statistically significant differences between the bioaccessibilities $(B / C)$ of the different fractions in each matrix, a Tukey's standarized range test (SAS version 9.3, SAS Inst. Inc., Cary, NC, USA) was used for the analysis. The level of significance was set at $P<0.05$. Significant differences among matrices in each fraction were analysed by the same approach.

\section{Results and discussion}

\subsection{Carotenoid concentrations}

The fractions isolated from each matrix (red carrots, red tomatoes, orange carrots and orange tomatoes) containing carotenoids with increasing levels of bio-encapsulation (carotenoid-enriched oil, chromoplast, small and large cell cluster fractions) were analysed for the initial carotenoid concentration.

Lycopene was the major carotenoid present in fractions obtained from red carrots and red tomatoes. $\beta$-Carotene was the main carotenoid in fractions obtained from orange carrots, whereas $\zeta$-carotene and another unknown carotenoid were the major carotenoids present in orange tomato fractions. However, as already explained, results for orange tomato fractions were expressed as equivalents of $\zeta$-carotene. Concentrations of the main carotenoids in the fractions obtained from each matrix are shown in Table 1.
3.2. Lycopene in vitro bioaccessibility in fractions of red tomatoes and red carrots

Fractions obtained from red tomato and red carrot fractions (carotenoid-enriched oil, chromoplast, small and large cell clusters) were prepared and the corresponding lycopene in vitro bioaccessibilities were measured.

The results for red carrot fractions (Fig. 2A) and red tomato fractions (Fig. 2B) show a clear decrease in lycopene in vitro bioaccessibility with increasing levels of lycopene bio-encapsulation.

It has been previously hypothesised that cell walls and chromoplast structures constitute important physical barriers against carotenoid release from the matrix and thus for subsequent incorporation into micelles (Jeffery, Holzenburg, et al., 2012; Lemmens et al., 2010; Tydeman et al., 2010; Xianquan, Shi, Kakuda, \& Yueming, 2005). Cell wall polysaccharides may impede micelle formation by entrapping lipids and bile salts, and by preventing digestive enzymes reaching the active compounds inside the cells for further digestion and absorption (Palafox-Carlos, Ayala-Zavala, \& González-Aguilar, 2011). At the same time, the chromoplast structure provides a stable environment for carotenoids, preventing their complete release and subsequent solubilisation, affecting both the stability and bioaccessibility (Schweiggert, Steingass, Heller, Esquivel, \& Carle, 2011).

Our results show direct evidence of barriers and therefore support the existing hypothesis, since lower lycopene bioaccessibility values were obtained in fractions where cell walls and chromoplasts were present as structural barriers. However, interesting differences were observed between fractions obtained from the two matrices (red carrots and red tomatoes), thus indicating that the matrix in which lycopene is embedded plays an important role.

For red carrots, the largest increase of lycopene bioaccessibility was obtained after the removal of the cell wall (i.e., the chromoplast fraction vs. the cell cluster fractions). The difference $(P<0.05)$ in lycopene in vitro bioaccessibility between cell clusters and the chromoplast fraction was significant. Lycopene in vitro bioaccessibility in red carrots was further increased after removal of the chromoplast barrier (lycopene solubilised in the oil phase), where a significant difference $(P<0.05)$ of the lycopene in vitro bioaccessibility was found between the carotenoid-enriched oil fraction and the three other fractions.

In the case of red tomatoes, the enhanced bioaccessibility was more pronounced when lycopene was solubilised in the oil fraction, rather than when cell walls were removed, as in red carrots. Statistical analysis showed that there was no significant difference $(P<0.05)$ between the lycopene in vitro bioaccessibilities in cell clusters and in chromoplast fractions of red tomatoes. Nevertheless, the lycopene bioaccessibility in the oil fraction was significantly higher $(P<0.05)$ than those in the other three fractions.

Further analysis showed that, for red carrots, cell walls and chromoplast substructure constitute important barriers against lycopene solubilisation while, in red tomatoes, the chromoplast substructure becomes the strongest obstacle hindering lycopene release during digestion. Therefore, it can be concluded that the cell wall is the most important barrier against lycopene bioaccessibility in case of red carrots, since a threefold increase of the lycopene bioaccessibility was obtained after isolation of the chromoplast fraction. The chromoplast substructure is also an important barrier against lycopene bioaccessibility, as a significant improvement (but to a lower extent) was found after isolating the carotenoid in the enriched oil fraction. For red tomatoes, however, the most important barrier is associated with the chromoplast substructure, as the solubilisation of lycopene in the enriched oil fraction was the most important step for increasing its bioaccessibility.

These observations clearly indicate that differences in cell wall composition and chromoplast substructure among the matrices 
Food Chemistry (2013), Vol. 141, p. 2036-2043, DOI: 10.1016/j.foodchem.2013.05.064

Journal homepage : www.elsevier.com/locate/foodchem

Table 1

Carotenoid concentration ( $\mu \mathrm{g} / \mathrm{g}$ fraction) (mean \pm standard deviation) in each fraction of red carrots, red tomatoes, orange carrots and orange tomatoes, respectively.

\begin{tabular}{|c|c|c|c|c|}
\hline & $\begin{array}{l}\text { Lycopene in red carrots } \\
(\mu \mathrm{g} / \mathrm{g})\end{array}$ & $\begin{array}{l}\text { Lycopene in red tomatoes } \\
(\mu \mathrm{g} / \mathrm{g})\end{array}$ & $\begin{array}{l}\beta \text {-Carotene in orange carrots } \\
(\mu \mathrm{g} / \mathrm{g})\end{array}$ & $\begin{array}{l}\zeta \text {-Carotene in orange tomatoes } \\
(\mu \mathrm{g} / \mathrm{g})\end{array}$ \\
\hline Carotenoid-enriched oil fraction & $3.04 \pm 0.05$ & $2.43 \pm 0.05$ & $4.39 \pm 0.28$ & $0.24 \pm 0.01$ \\
\hline Chromoplast fraction & $45.8 \pm 1.81$ & $36.2 \pm 0.98$ & $25.8 \pm 11.46$ & $3.35 \pm 0.13$ \\
\hline Small cell cluster fraction & $46.3 \pm 0.51$ & $10.9 \pm 0.45$ & $21.1 \pm 4.95$ & $4.89 \pm 0.12$ \\
\hline Large cell cluster fraction & $27.8 \pm 6.10$ & $45.1 \pm 1.25$ & $6.96 \pm 0.43$ & $3.96 \pm 0.57$ \\
\hline
\end{tabular}
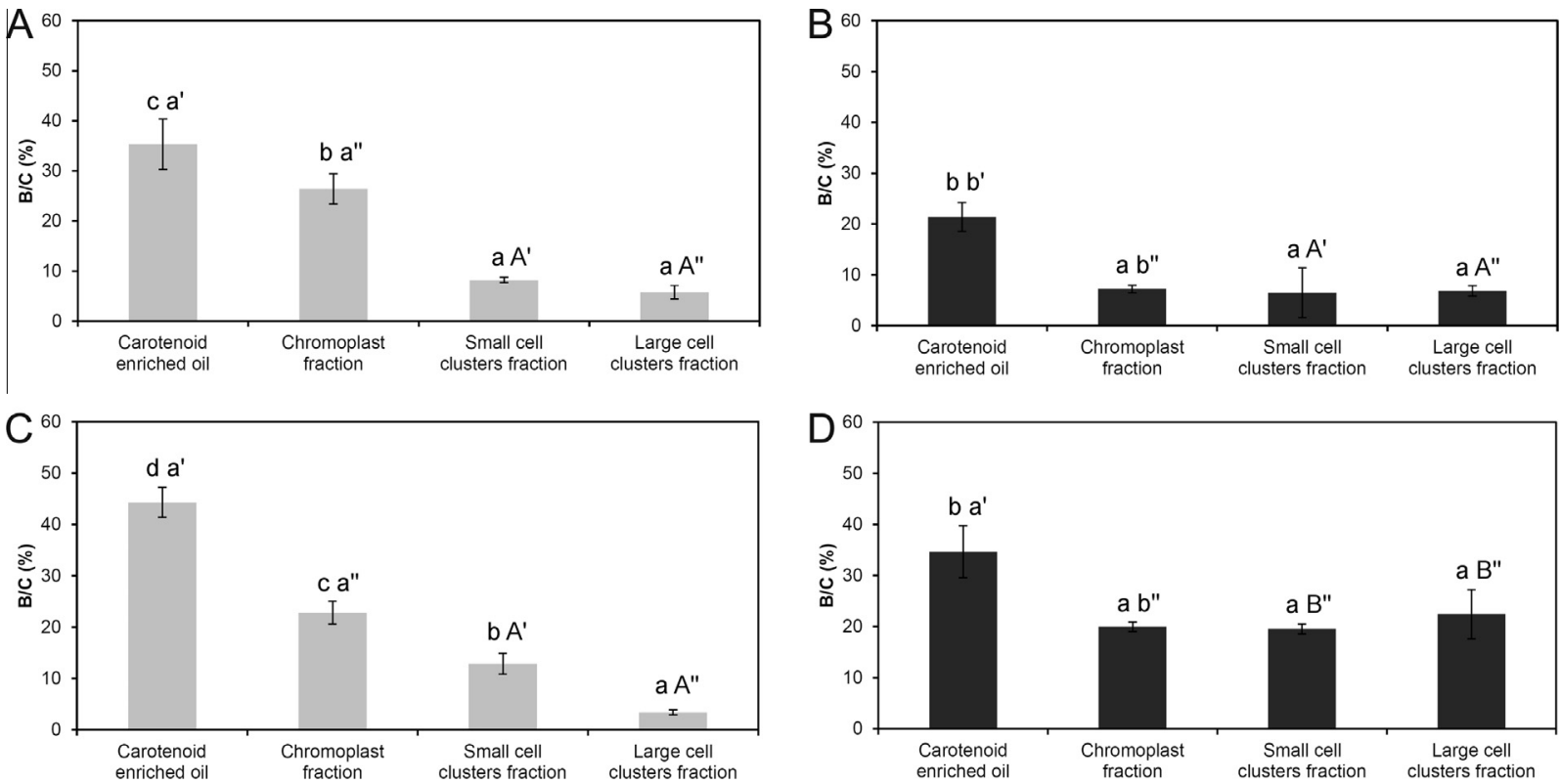

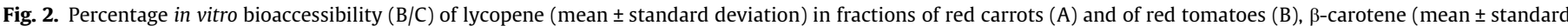

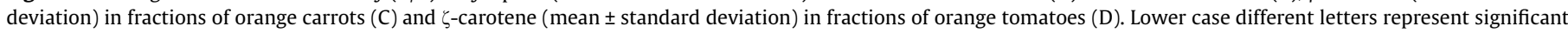

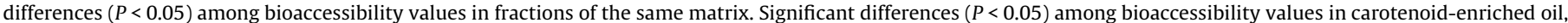

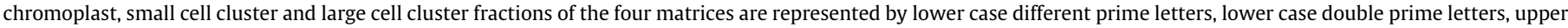
case prime letters and upper case double prime letters, respectively.

are important factors determining carotenoid bioaccessibility. This is in line with previous suggestions that pectin composition and the presence of other polysaccharides (which vary according to the matrix) in the cell wall influence the bioaccessibility of carotenoids by interacting differently with the target compounds (Castenmiller \& West, 1998; Epriliati, D’Arcy, \& Gidley, 2009; Parada \& Aguilera, 2007).

In the literature, some important differences between carrot and tomato cell wall material, which may be related to differences in carotenoid bioaccessibility, can be found. For example, Jeffery, Holzenburg, et al. (2012) recently reported that the cell wall in carrots is very fibrous and compact and pectin may reduce cell wall porosity. In tomato, cell walls are thinner and less fibrous than in carrots, and present higher porosity due to their tendency to lose cellular adhesion. These suggestions are in line with our results. The cell walls in red carrots are fibrous and compact, therefore acting as an important barrier against lycopene bioaccessibility. By contrast, red tomato cell walls, due to their higher porosity, do not determine lycopene bioaccessibility, and the chromoplast substructure becomes the main barrier.

When the absolute values for the lycopene bioaccessibility between red carrot and red tomato fractions are compared, it can be observed that, for red carrot chromoplast fractions, the lycopene bioaccessibility was significantly higher $(P<0.05)$ than that for the fractions of red tomato (Fig. $2 \mathrm{~A}$ and $\mathrm{B}$ ). Fig. 3 represents the microscopic observations of chromoplast fractions of different matrices in this study. Red carrot (A) and red tomato (B) chromoplasts contained crystalline carotene substructures, which have been observed previously too by Schweiggert et al. (2012), Jeffery, Holzenburg, et al. (2012), Kim, Rensing, Douglas, and Cheng (2010) and Shi and Le Maguer (2000). Among the different chromoplast morphologies, containing globular, tubular, reticulotubular, membranous and crystalline substructures, chromoplasts containing carotenoids in the solid crystalline state are known to result in the poorest bioaccessibility (Fleshman et al., 2011). However, although both matrices present the same chromoplast morphology, differences in lycopene in vitro bioaccessibility of the two chromoplast fractions indicate that, besides the crystalline state of the carotenoids, the chromoplast sub-organisation, as well as other matrix effects, probably also have an important effect on the subsequent solubility and incorporation into the micelles. Schweiggert et al. (2011) already indicated that the release of lycopene is different between several fruit matrices because of its different association with other chromoplast substructures, such as the thylakoid membranes and its localisation within the organelle. In the case of the two studied matrices studied here, the carrot root chromoplasts accumulate carotenoids inside the lumina of the thylakoid membranes while, in tomato fruits, they accumulate in membrane-shaped structures as carotenoid-protein complexes or are membrane bound (Egea et al., 2010; Shi \& Le Maguer, 2000). Such characteristics may explain the differences in lycopene bioaccessibility among chromoplast fractions of red carrots and red tomatoes.

In the carotenoid-enriched oil fraction, the lycopene in vitro bioaccessibility value was highly improved for both matrices. 

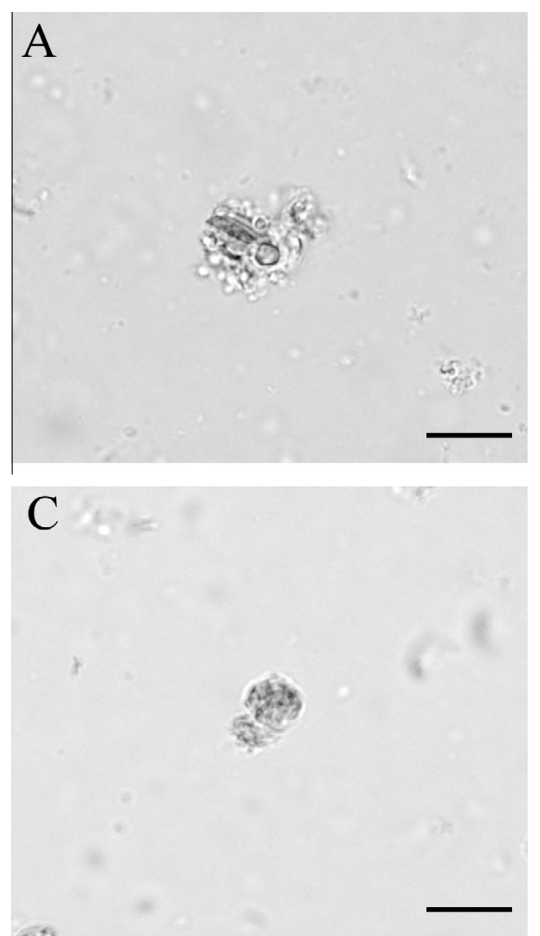
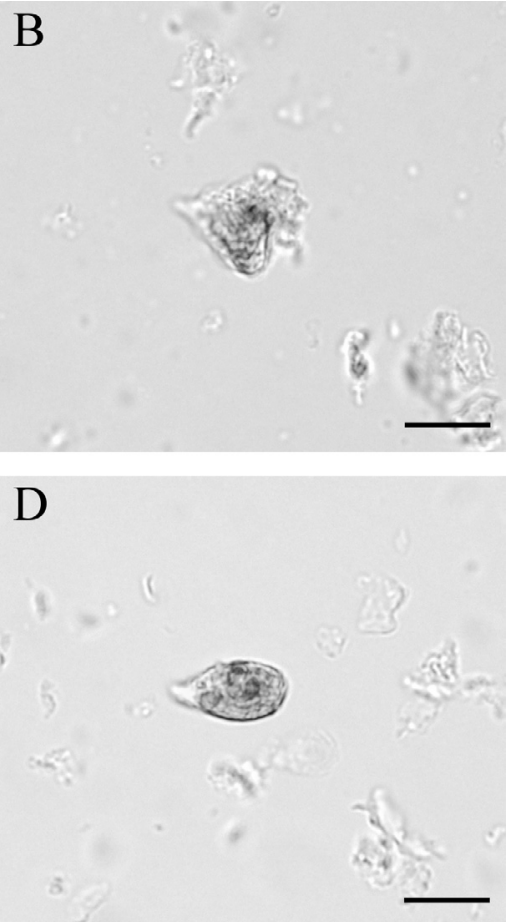

Fig. 3. Isolated chromoplasts from red carrot (A), red tomato (B), orange carrot (C) and orange tomato (D). Scale bars $=10 \mu \mathrm{m}$.

Crystalline structures of carotenoids found in tomatoes and carrot roots can be dissolved in oil, resulting in a higher bioaccessibility (Colle et al., 2012; Fernández-García, Mínguez-Mosquera, \& Pérez-Gálvez, 2007; Vásquez-Caicedo, Heller, Neidhart, \& Carle, 2006). Similar to the chromoplast fraction, the lycopene bioaccessibility was higher in the carotenoid-enriched oil isolated from red carrots, compared to red tomatoes. Solubilisation of carotenoids into the oil phase is greatly dependent on the polarity of the molecule (Nguyen, Francis, \& Schwartz, 2001; Tyssandier, Lyan, \& Borel, 2001). Lycopene is a highly lipophilic molecule which, in order to be isolated from the matrix, has to be transferred first from the innermost physical barrier (chromoplast), across the cell wall and move through the aqueous environment surrounding the cells, which might be considered an additional physical barrier for carotenoid incorporation into the oil phase. Considering, the same type of carotenoid within different matrices, differences in matrix characteristics, previously described, may influence lycopene transfer through the chromoplast substructure and cell wall into the oil phase.

\section{3. $\beta$-Carotene in vitro bioaccessibility in fractions of orange carrots}

Orange carrot fractions (carotenoid-enriched oil, chromoplasts, small and large cell clusters) were prepared and the corresponding $\beta$-carotene in vitro bioaccessibility was measured.

Fig. $2 \mathrm{C}$ shows the values of the $\beta$-carotene in vitro bioaccessibilty. An increased $\beta$-carotene bioaccessibility with a decreasing level of barriers can be observed. There was a significant difference $(P<0.05)$ in $\beta$-carotene in vitro bioaccessibilities among the four fractions.

Cell walls and chromoplast substructure were confirmed to be important physical barriers that hamper the release of $\beta$-carotene from the matrix, a behaviour which was also observed in red carrots. Once $\beta$-carotene is dissolved in the carotenoid-enriched oil fraction, the percentage of in vitro bioaccessibility increased six times compared to the value obtained for the large cell cluster fraction. In the latter fraction, cell walls and chromoplast substructures were impeding the $\beta$-carotene solubilisation and incorporation into micelles.

Similar to the lycopene-rich chromoplasts from red carrots, chromoplasts from orange carrots, which contain $\beta$-carotene as the main carotenoid, showed a crystalline carotene substructure (Fig. 3C). Kim et al. (2010), Schweiggert et al. (2012), Jeffery, Holzenburg, et al. (2012) and Hornero-Méndez and Mínguez-Mosquera (2007) came to similar conclusions for orange carrots. The crystalline substructure, in the chromoplasts from orange carrots, is an important characteristic that determines the low $\beta$-carotene bioaccessibility. As mentioned in the previous section, from the different types of chromoplast morphologies, the crystalline carotene substructure presents the lowest carotenoid bioaccessibility.

When the $\beta$-carotene bioaccessibility in orange carrots is compared to the lycopene bioaccessibility in red carrots (same matrix, different type of carotenoid) in each matrix, no significant differences $(P<0.05)$ were found. This might indicate that the structural matrix of the two types of carrots is affecting the lycopene and $\beta$ carotene in vitro bioaccessibility in a similar way. Interestingly in this case, the differences of the molecular structure, and hence polarity, between lycopene and $\beta$-carotene in carrots do not seem to be a major factor affecting solubilisation into the micelles.

\section{4. $\zeta$-Carotene in vitro bioaccessibility in fractions of orange tomatoes}

Orange tomato fractions (carotenoid-enriched oil, chromoplasts, small and large cell clusters) were prepared and $\zeta$-carotene in vitro bioaccessibility was measured. Fig. 2-D shows the results of the $\zeta$-carotene in vitro bioaccessibility for the fractions of orange tomatoes. No significant differences $(P<0.05)$ for the $\zeta$-carotene in vitro bioaccessibility between chromoplast, small and large cell clusters fractions could be observed. Once $\zeta$-carotene was solubilised in the oil fraction (absence of cellular material and chromoplast substructures), there was a significant enhancement $(P<0.05)$ of its bioaccessibility. 
Similar to what was observed for the lycopene bioaccessibility in red tomatoes, the results suggest that the chromoplast morphology is more important in determining the $\zeta$-carotene bioaccessibility than is the cell wall itself. In contrast to the chromoplast barrier, the removal of the cell walls did not result in a significant improvement of $\zeta$-carotene bioaccessibility in orange tomato fractions.

It was observed by Rosso (1967) that chromoplast morphologies from different members of the family Solanaceae (to which tomatoes belong) are not the same. Using electron microscopy, chromoplast substructures from the Golden Jubilee tomatoes (with $\zeta$-carotene and pro-lycopene as the major carotenoids) appeared as spheroidal globules and crystals. From our light microscopy observations, globules of various sizes in orange tomato chromoplasts were observed (Fig. 3D). The globules clearly differed from the high amount of crystals observed in red tomatoes (Fig. 3B). This structural difference may explain why the $\zeta$-carotene in vitro bioaccessibility, in all fractions of orange tomatoes, was significantly higher $(P<0.05)$ than that for lycopene in fractions from red tomatoes. Probably, the crystalline substructures of the lycopene-rich chromoplasts from red tomatoes confer a high resistance to lycopene solubilisation and subsequent incorporation into micelles. It has been previously reported by Fleshman et al. (2011) that melon chromoplasts with globular substructures show a higher $\beta$-carotene bioaccessibility than do carrot root chromoplasts with crystalline substructures. Jeffery, Turner, et al. (2012) similarly concluded that globular carotenoids are the most prone to solubilisation during digestion. Schweiggert et al. (2012) also detected a higher bioaccessibility of $\beta$-carotene in mango and papaya, in which carotenoids are deposited in lipid elements in the chromoplasts, compared to tomatoes and carrots, where carotenoids are encountered as solid crystalline substructures.

The observations in orange tomatoes support the hypothesis that the chromoplast morphology and its substructures are important determinants of the carotenoid bioaccessibility. Additionally, differences in cell wall composition between orange and red tomatoes might play a role.

\section{Conclusion}

Several previous studies have investigated carotenoid bioaccessibility in different fruit- and vegetable-based systems. However, there is a remaining problem of the detailed understanding of carotenoid bioaccessibility in relation to (natural and/or processinduced) structural physical characteristics of the matrix. Our experiment was a targeted study, using specific separate fractions, in which the most important barriers governing carotenoid bioaccessibility (cell walls/membranes and chromoplast structure/organisation) were systematically considered. This allowed improved insight of how the different levels of carotenoid physical bioencapsulation affected their release, solubilisation and incorporation in micelles during digestion. The results of this experiment show an inverse correlation between the levels of carotenoid bioencapsulation and the carotenoid in vitro bioaccessibility. Observations of the bioaccessibility of different carotenoids in fractions of different matrices emphasise the importance of the type of carotenoid (although to a limited extent in this study) and the matrixrelated effects (cell wall material composition and chromoplast morphology and substructure organisation) on carotenoid solubilisation and subsequent incorporation into the micelles.

It becomes evident that, depending on the food matrix considered, specific barriers are important. In the case of carrots (red and orange), the chromoplast substructure is an important barrier for carotenoid bioaccessibility, but the cell wall appears to be the most important barrier for obtaining a more significant improvement. For tomatoes (red and orange) the chromoplast substructure proves to be the principal barrier affecting carotenoid bioaccessibility. Higher $\zeta$-carotene in vitro bioaccessibility in fractions of orange tomatoes than in fractions of the other matrices studied, supports the hypothesis that crystalline chromoplast substructures (observed in red carrots, red tomatoes, and orange carrots) result in a lower carotenoid bioaccessibility.

Nevertheless, in order to obtain the highest increase in carotenoid bioaccessibility in the four matrices, it is necessary to solubilise carotenoids in the oil phase. Therefore, detailed knowledge of how to improve the transfer of carotenoids to the oil phase of food systems during processing and/or digestion is of key importance for developing foods with enhanced levels of bioaccessible carotenoids.

\section{Acknowledgements}

This research was financially supported by the European Commission, Seventh Framework Programme (FP7), Marie Curie Actions 'HST Food Train'. Lien Lemmens is a postdoctoral researcher funded by the Research Fund KU Leuven.

\section{References}

Anese, M., Mirolo, G., Beraldo, P., \& Lippe, G. (2013). Effect of ultrasound treatments of tomato pulp on microstructure and lycopene in vitro bioaccessibility. Food Chemistry, 136, 458-463.

Bengtsson, A., Brackmann, C., Enejder, A., Alminger, M. L., \& Svanberg, U. (2010). Effects of thermal processing on the in vitro bioaccessibility and microstructure of $\beta$-carotene in orange-fleshed sweet potato. Journal of Agricultural and Food Chemistry, 58(20), 11090-11096.

Britton, G. (1995). Structure and properties of carotenoids in relation to function. FASEB Journal, 9(15), 1551-1558.

Castenmiller, J., \& West, C. (1998). Bioavailability and bioconversion of carotenoids Annual Review of Nutrition, 18(1), 19-38.

Cheniclet, C., Rong, W. Y., Causse, M., Frangne, N., Bolling, L., Carde, J. P., et al. (2005). Cell expansion and endoreduplication show a large genetic variability in pericarp and contribute strongly to tomato fruit growth. Plant Physiology, 139, 1984-1994.

Colle, I., Van Buggenhout, S., Lemmens, L., Van Loey, A., \& Hendrickx, M. (2012). The type and quantity of lipids present during digestion influence the in vitro bioaccessibility of lycopene from raw tomato pulp. Food Research International, 45(1), 250-255.

Colle, I., Van Buggenhout, S., Van Loey, A., \& Hendrickx, M. (2010). High pressure homogenization followed by thermal processing of tomato pulp: Influence on microstructure and lycopene in vitro bioaccessibility. Food Research International, 43(8), 2193-2200.

Degrou, A., George, S., Renard, C., \& Page, D. (2013). Physicochemical parameters that influence carotenoids bioaccessibility from a tomato juice. Food Chemistry, $136,435-441$.

Egea, I., Barsan, C., Bian, W., Purgatto, E., Latche, A., Chervin, C., et al. (2010). Chromoplast differentiation: Current status and perspectives. Plant and Cell Physiology, 51(10), 1601-1611.

Epriliati, I., D’Arcy, B., \& Gidley, M. (2009). Nutriomic analysis of fresh and processed fruit products. 1. During in vitro digestions. Journal of Agricultural and Food Chemistry, 57(8), 3363-3376.

Fernández-García, E., Mínguez-Mosquera, M., \& Pérez-Gálvez, A. (2007). Changes in composition of the lipid matrix produce a differential incorporation of carotenoids in micelles. Interaction effect of cholesterol and oil. Innovative Food Science \& Emerging Technologies, 8(3), 379-384.

Fleshman, M. K., Lester, G. E., Riedl, K. M., Kopec, R. E., Narayanasamy, S., Curley, R. W., et al. (2011). Carotene and novel apocarotenoid concentrations in orangefleshed cucumis melo melons: Determinations of $\beta$-carotene bioaccessibility and bioavailability. Journal of Agricultural and Food Chemistry, 59(9), 4448-4454.

Granado-Lorencio, F., Olmedilla-Alonso, B., Herrero-Barbudo, C., Blanco-Navarro, I., Pérez-Sacristan, B., \& Blázquez-García, S. (2007). In vitro bioaccessibility of carotenoids and tocopherols from fruits and vegetables. Food Chemistry, 102(3), 641-648.

Hansen, L., \& Chiu, M. (2005). Isolation and composition of chromoplasts from tomatoes. Journal of Agricultural and Food Chemistry, 53, 6678-6682.

Holst, B., \& Williamson, G. (2008). Nutrients and phytochemicals: From bioavailability to bioefficacy beyond antioxidants. Current Opinion in Biotechnology, 19(2), 73-82.

Hornero-Méndez, D. \& Mínguez-Mosquera, M. (2007). Bioaccessibility of carotenes from carrots: Effect of cooking and addition of oil. Innovative Food Science $\mathcal{E}$ Emerging Technologies, 8(3), 407-412.

Jeffery, J., Holzenburg, A., \& King, S. (2012a). Physical barriers to carotenoid bioaccessibility. Ultrastructure survey of chromoplast and cell wall morphology in nine carotenoid-containing fruits and vegetables. Journal of the Science of Food and Agriculture, 92, 2594-2602. 
Jeffery, J., Turner, N. D., \& King, R. (2012b). Carotenoid bioaccessibility from nine raw carotenoid-storing fruits and vegetables using an in vitro model. Journal of the Science of Food and Agriculture, 92, 2603-2610.

Key, T. J. (2011). Fruit and vegetables and cancer risk. British Journal of Cancer 104(1), 6-11.

Kim, J., Rensing, K., Douglas, C., \& Cheng, K. (2010). Chromoplasts ultrastructure and estimated carotene content in root secondary phloem of different carrot varieties. Planta, 231(3), 549-558.

Knockaert, G., Lemmens, L., Van Buggenhout, S., Hendrickx, M., \& Van Loey, A. (2012). Changes in $\beta$-carotene bioaccessibility and concentration during processing of carrot puree. Food Chemistry, 133(1), 60-67.

Lemmens, L., Van Buggenhout, S., Oey, I., Van Loey, A., \& Hendrickx, M. (2009). Towards a better understanding of the relationship between the $\beta$-carotene in vitro bio-accessibility and pectin structural changes: A case study on carrots. Food Research International, 42(9), 1323-1330.

Lemmens, L., Van Buggenhout, S., Van Loey, A., \& Hendrickx, M. (2010). Particle size reduction leading to cell wall rupture is more important for the $\beta$-carotene bioaccessibility of raw compared to thermally processed carrots. Journal of Agricultural and Food Chemistry, 58(24), 12769-12776.

Mackinney, G., \& Jenkins, J. A. (1949). Inheritance of carotenoid differences in Lycopersicon esculentum strains. Genetics, 35, 284-291.

Ness, A. R., \& Powles, J. W. (1997). Fruit and vegetables, and cardiovascular disease: A review. International Journal of Epidemiology, 26(1), 1-13.

Nguyen, M., Francis, D., \& Schwartz, S. (2001). Thermal isomerisation susceptibility of carotenoids in different tomato varieties. Journal of the Science of Food and 'Connell, O., Ryan, L., \& O'Bri

bioaccessible from fruits than 258-264.

O’Sullivan, L., Galvin, K., Aherne, S. A., \& O’Brien, N. M. (2010). Effects of cooking on the profile and micellarization of 9-cis-, 13-cis- and all-trans- $\beta$-carotene in green vegetables. Food Research International, 43, 1130-1135.

Palafox-Carlos, H., Ayala-Zavala, J. F., \& González-Aguilar, G. A. (2011). The role of dietary fibre in the bioaccessibility and bioavailability of fruit and vegetable antioxidants. Journal of Food Science, 76(1), R6-R15.

Parada, J., \& Aguilera, J. (2007). Food microstructure affects the bioavailability of several nutrients. Journal of Food Science, 72(2), R21-R32.

Rao, A. V., \& Rao, L. G. (2007). Carotenoids and human health. Pharmacological Research, 55, 207-216.

Reboul, E. Richelle, M., Perrot, E., Desmoulins-Malezet, C., Pirisi, V. \& Borel, P. (2006). Bioaccessibility of carotenoids and vitamin E from their main dietary sources. Journal of Agricultural and Food Chemistry, 54(23), 8749-8755.

Rich, G., Bailey, A., Faulks, R., Parker, M., Wickham, M., \& Fillery-Travis, A. (2003). Solubilization of carotenoids from carrot juice and spinach in lipid phases: I. Modeling the gastric lumen. Lipids, 38(9), 933-945.

Rosso, S. (1967). An ultrastructural study of the mature chromoplasts of the tangerine tomato (Lycopersicon esculentum var. Golden Jubilee). Journal of Ultrastructure Research, 20, 179-189.
Ryan, L., O'Connell, O., O’Sullivan, O., Aherne, S., \& O'Brien, N. (2008). Micellarisation of carotenoids from raw and cooked vegetables. Plant foods for human nutrition (formerly qualitas plantarum), 63(3), 127-133.

Sadler, G., Davis, J., \& Dezman, D. (1990). Rapid extraction of lycopene and $\beta$ carotene from reconstituted tomato paste and pink grapefruit homogenates. Journal of Food Science, 55, 1460-1461.

Schweiggert, R. M., Mezger, D., Schimpf, F., Steingass, C. B., \& Carle, R. (2012). Influence of chromoplast morphology on carotenoid bioaccessibility of carrot, mango, papaya, and tomato. Food Chemistry, 135, 2736-2742.

Schweiggert, R., Steingass, C., Heller, A., Esquivel, P., \& Carle, R. (2011). Characterization of chromoplasts and carotenoids of red- and yellow-fleshed papaya. Planta, 234(5), 1031-1044.

Shi, J., \& Le Maguer, M. (2000). Lycopene in tomatoes: Chemical and physical properties affected by food processing. Critical Reviews in Biotechnology, 20, 293-334.

Steinmetz, K. A., \& Potter, J. D. (1996). Vegetables, fruit, and cancer prevention: A review. Journal of the American Dietetic Association, 96(10), 1027-1039.

Tydeman, E., Parker, M., Wickham, M., Rich, G., Faulks, R., Gidley, M., et al. (2010). Effect of carrot (Daucus carota) microstructure on carotene bioaccessibilty in the upper gastrointestinal tract. 1. In vitro simulations of carrot digestion. Journal of Agricultural and Food Chemistry, 58(17), 9847-9854.

Tyssandier, V., Lyan, B., \& Borel, P. (2001). Main factors governing the transfer of carotenoids from emulsion lipid droplets to micelles. Biochimica et Biophysica Acta (BBA) - Molecular and Cell Biology of Lipids, 1533(3), 285-292.

Van Buggenhout, S., Alminger, M., Lemmens, L., Colle, I., Knockaert, G., Moelants, K., et al. (2010). In vitro approaches to estimate the effect of food processing on carotenoid bioavailability need thorough understanding of process induced microstructural changes. Trends in Food Science \& Technology, 21(12), 607-618.

getables in the prevention of cancer and cardiovascular disease. Public Health Nutrition, 3, 103-107

Vásquez-Caicedo, A. L., Heller, A., Neidhart, S., \& Carle, R. (2006). Chromoplast morphology and $\beta$-carotene accumulation during postharvest ripening of mango cv. 'Tommy Atkins'. Journal of Agricultural and Food Chemistry, 54(16), 5769-5776

Veda, S., Kamath, A., Platel, K., Begum, K., \& Srinivasan, K. (2006). Determination of bioaccessibility of beta-carotene in vegetables by in vitro methods. Molecular Nutrition E' Food Research, 50(11), 1047-1052.

Vishnevetsky, M., Ovadis, M., \& Vainstein, A. (1999). Carotenoid sequestration in plants: The role of carotenoid-associated proteins. Trends in Plant Science, 4(6), 232-235.

Waldron, K. W., Parker, M. L., \& Smith, A. C. (2003). Plant cell walls and food quality. Comprehensive Reviews in Food Science and Food Safety, 2, 101-119.

Xianquan, S., Shi, J., Kakuda, Y., \& Yueming, J. (2005). Stability of lycopene during food processing and storage. Journal of Medicinal Food, 8(4), 413-422. 